\title{
Educação ambiental e preservação da biodiversidade: relato de um estudo de caso com a fauna pantaneira
}

\author{
Carlos Rodrigo Lehn \\ Instituto Federal de Educação, Ciência e Tecnologia de Mato Grosso do Sul, campus Coxim, carlos.lehn@ifms.edu.br
}

Paulo Francis Florencio Dutra

Instituto Federal de Educação, Ciência e Tecnologia de Mato Grosso do Sul, campus Aquidauana, paulo.dutra@ifms.edu.br

Airton José Vinholi Júnior

Instituto Federal de Educação, Ciência e Tecnologia de Mato Grosso do Sul, campus Ponta Porã, airton.vinholi@ifms.edu.br

\section{Resumo}

A Educação Ambiental é direito garantido por legislação vigente e, ainda hoje, temática distante da educação básica em todo o Brasil. Ao mesmo passo em que a população mundial cresce aceleradamente, cresce também a necessidade de fazer com que práticas ambientais responsáveis estejam inseridas no cotidiano das pessoas. Ao longo de muitos anos, o ensino de Biologia tem sido pouco contextualizado, fazendo com que o aprendizado tenha pouco significado para o aluno. Assim, procura-se investigar a importância da abordagem da Educação Ambiental por meio da aplicação de um questionário utilizando espécies nativas da fauna pantaneira e também espécies exóticas, no qual os resultados evidenciaram que o percentual de acerto para as espécies nativas foi de apenas 37\%, enquanto que para as exóticas, especialmente africanas, este percentual ultrapassa $80 \%$ dos acertos. A preservação da biodiversidade depende do desenvolvimento massivo de uma geração ambientalmente consciente, e, para que se possa alcançar esse patamar de conscientização, a Educação Ambiental é considerada peça chave em todo o processo.

Palavras-chave: Meio Ambiente, Ensino contextualizado, Sujeito ecológico, Tema transversal

\section{Environmental education and biodiversity conservation: a case study}

\begin{abstract}
Environmental Education is a right guaranteed by the law and nowadays, a subject that is far from the Basic Education in Brazil. At the same time that the world's population grows really fast, it grows the necessity of making responsible environmental practices in people's routine. Over many years the Biology teaching hasn't been contextualized as it should be, in this way the learning process hasn't been effective for the student. In this way, we tried to search the importance of the Environmental Education approach having a questionnaire. The application of a questionnaire using native species of wetland wildlife and exotic species, showed that the percentage of accuracy for native was only $37 \%$ while for exotic species, especially in Africa, this percentage exceeds $80 \%$. The preservation of our biodiversity depends on the massive development of an environmentally conscious generation in a way that we can reach the level of awareness and environmental education is considered a key element in the process.
\end{abstract}

Key-words: Environment, Contextualized Education, Ecological Subject, Transversal theme.

\section{Introdução}

"Todos têm direito a um meio ambiente ecologicamente equilibrado, bem de uso comum do povo e essencial à sadia qualidade de vida, impondo-se ao poder público e à coletividade o dever de defendê-lo e preservá-lo para as presentes e futuras gerações". Este trecho inicial do artigo 225 da Constituição da República Federativa do Brasil (CF) chama a atenção para a responsabilidade atribuída aos cidadãos comuns quanto à preservação do meio ambiente.

Ao mesmo passo em que todos são cobrados a apresentar uma postura responsável com relação ao meio ambiente, é 
preciso se questionar sobre o papel incumbido ao poder público de forma a garantir a efetividade desse direito.

O parágrafo $1^{\circ}$ do artigo 225 da CF em seu inciso VI cita "promover a educação ambiental em todos os níveis de ensino e a conscientização pública para a preservação do meio ambiente". Nesse contexto, subtende-se que durante toda a formação educacional a educação ambiental deve ser um tema do cotidiano, relacionado diretamente com todas as atividades escolares (Lehn, 2009), para que assim uma compreensão integrada acerca do meio ambiente e suas múltiplas e complexas relações possa ser desenvolvida.

Ainda que as primeiras lutas ecológicas no Brasil datem dos anos 70, foi principalmente a partir da década de 80 que entraram em cena os novos movimentos sociais, entre os quais o ecologismo (Carvalho, 2008). A Educação Ambiental é, sem dúvida, parte do movimento ecológico, nascida diretamente da preocupação da sociedade em garantir qualidade de vida para os habitantes atuais do planeta assim como aos futuros, contemplando o conceito mais difundido de desenvolvimento sustentável.

A lei 9.795, de 27 de abril de 1999, dispõe sobre a Educação Ambiental e institui a política nacional de Educação Ambiental. De acordo com essa lei, entende-se por Educação Ambiental os processos por meio dos quais indivíduo e coletividade constroem valores sociais, conhecimentos, habilidades, atitudes e competências voltadas para a conservação do meio ambiente, bem de uso comum do povo, essencial à sadia qualidade de vida e sua sustentabilidade.

Deve-se entender a Educação Ambiental como um componente essencial e permanente da educação nacional, tendo papel fundamental para o desenvolvimento massivo de uma sociedade ambientalmente consciente (Carvalho, 2005). De acordo com Jacobi (2003), a Educação Ambiental que está sendo aplicada no país é diversa e restrita a presença de órgãos do governo articulando, promovendo e coordenando as ações. Apesar de muitos avanços, a educação ambiental, ainda hoje, não é aplicada de maneira satisfatória.

Passados mais de 20 anos da promulgação da CF e 12 anos da lei 9795/99, o que se observa é que muitas escolas, em todo o Brasil, ainda não adaptaram suas ementas de forma a incluir a abordagem da Educação Ambiental em caráter multidisciplinar. Talvez o que não esteja claro para as coordenações pedagógicas escolares é que não se está falando da educação ambiental como disciplina na grade curricular. O Plano Nacional de Educação - PNE (período de 2001 à 2010), aprovado pelo Congresso Nacional sob a lei 10.172, 9 de janeiro de 2001, propõe que a Educação Ambiental deve ser tratada como tema transversal e desenvolvida como prática educativa integrada, contínua e permanente em conformidade com a lei n. ${ }^{\circ}$ 9795/99.

$\mathrm{O}$ aprofundamento de temas, que estão ligados à biodiversidade e ao meio ambiente, possibilitado por meio da educação e divulgação científica, é essencial para a conservação da natureza e para a formação de cidadãos responsáveis ambientalmente. Algumas disciplinas, naturalmente apresentam maior afinidade com a temática ambiental, como Ciências e Biologia. Entretanto, indiferente de qual for a disciplina, toda temática que gira em torno da Educação Ambiental deve primar pelo desenvolvimento de uma visão integrada do meio ambiente em suas múltiplas e complexas relações, envolvendo aspectos ecológicos, psicológicos, políticos, sociais, econômicos, científicos, culturais e éticos, assim evidenciado no artigo $5^{\circ}$ da lei $9.795 / 99$.

Ao longo de muitos anos, o ensino de Biologia tem se mostrado pouco contextualizado, fazendo com que muitas vezes os conteúdos ministrados se mostrem sem significado para os alunos. Persistindo em um ensino tradicional básico, compartimentado e abstrato, não há possibilidades da análise de problemas locais (Grynszpan, 1999). Em se tratando de Educação Ambiental, esta pode ser considerada uma questão fundamental, pois buscar alternativas depende, obrigatoriamente, da habilidade de sensibilização.

Algumas proposições de Educação Ambiental dão ênfase ao processo científico (corrente científica), com o objetivo de abordar com rigor as realidades e problemáticas ambientais e de compreendê-las melhor, identificando mais especificamente as relações de causa e efeito (Sauvé, 2005).

O presente trabalho tem como objetivo avaliar o conhecimento que um grupo de alunos possui sobre a fauna local e discutir a relação desse conhecimento com a educação ambiental.

\section{Desenvolvimento da temática}

A população do planeta se aproxima dos sete bilhões de pessoas com estimativas ultrapassando 12 bilhões de pessoas para o ano de 2050. Da mesma forma que a população global aumenta em ritmo acelerado, aumenta também a pressão sobre os recursos naturais, para que todo esse crescimento possa ser sustentado. Assim, cada vez mais, as ações diárias requerem responsabilidade sendo indispensável que tenham um caráter sustentável.

A Educação Ambiental, em seu caráter formal e multidisciplinar, tem sido considerada uma ferramenta imprescindível para a formação de uma geração ambientalmente consciente. À medida que se cresce em contato com a temática ambiental, práticas positivas com relação ao meio ambiente passam a ser inerentes ao indivíduo e assim o sujeito ecológico começa a ser trabalhado. A identidade do sujeito ecológico está fundamentada no ideário ecológico que se reflete no modo de ser e viver (Carvalho, 2008).

Um dos maiores desafios que os educadores possuem 
nos dias de hoje está em promover a contextualização dos conteúdos ministrados, fazendo com que o ensino tenha maior significado para o aluno. O mesmo é verdadeiro quando se trata de assuntos voltados para a preservação da biodiversidade.

Durante muito tempo, assim como atualmente, o ensino de zoologia, tanto no ensino fundamental quanto no ensino médio, tem sido feito utilizando como exemplo espécies exóticas, em especial nativas do continente africano, como girafas, leões, zebras, avestruzes e também asiáticas, como urso panda e tigre. Mesmo o Brasil sendo considerado um país megadiverso, a fauna nacional é pouco conhecida e em parte a educação oferecida nos dias de hoje tem sua parcela de culpa.

Como promover a preservação de algo que sequer é conhecido? Graipel et al. (2008) reportam que é preciso divulgar para proteger e que a sociedade precisa conhecer outros animais além dos que vivem na África. E isso não se refere apenas a questões relacionadas exclusivamente à escola, pelo contrário, a implementação de políticas públicas sólidas e concretas, que visem à preservação de espécies através da criação de unidades de conservação voltadas para tal fim, depende também desse conhecimento.

Um questionário envolvendo imagens de dez animais exóticos e outros dez nativos do Pantanal aplicado a alunos do Ensino Médio do Instituto Federal de Educação, Ciência e Tecnologia de Mato Grosso do Sul (IFMS), campus Coxim, nos dias 21 e 22 de outubro de 2011, demonstra que, entre os 60 alunos entrevistados, o percentual de acertos para as espécies exóticas ultrapassa $82 \%$. Já para as espécies nativas o percentual de acerto cai para menos de $37 \%$. Mesmo para espécies comuns em áreas urbanas em todo o país, como é o caso do gambá (Didelphis albiventris), marsupial de hábitos noturnos, apenas 5\% dos participantes demonstraram conhecer tal espécie. Além do gambá, a lista de espécies nativas incluía também, entre outras, o tamanduá-bandeira (Myrmecophaga tridactyla), ariranha (Pteronura brasiliensis), tucanuçu (Ramphastos toco), anta (Tapirus terrestris), tamanduá-mirim (Tamandua tetradactyla) e a espécie regionalmente conhecida como lobinho (Cerdocyon thous).

Entre os alunos questionados, participaram estudantes que integram o Grupo de Educação Ambiental do IFMS - campus Coxim. Quando foram questionados sobre a importância de se preservar a biodiversidade, reportaram, de forma praticamente unânime, que é preciso conhecer aquilo a que se propõe preservar, como pode ser observado nos seguintes depoimentos:

“É importante preservar, pois somente conhecendo o habitat de cada animal seremos capazes de preservá-lo e assim não restringir seu local de vida".
"Sim, é importante conhecer, pois como seremos capazes de preservar algo que não conhecemos?”.

"Somente estudando as espécies seremos capazes de estabelecer a melhor maneira para preservá-las".

"Sim, precisamos conhecer e preservar as espécies".

O teor das respostas fornecidas se mostra semelhante aos resultados apresentados em Charlot e da Silva (2005), segundo os quais mais de $94,3 \%$ dos participantes, incluindo estudantes brasileiros e franceses, afirmaram acreditar que a natureza esteja realmente ameaçada em todo o mundo.

Muitos especialistas argumentam que a solução dos maiores problemas ambientais passa, ao menos em um primeiro momento, pelo surgimento de uma geração ambientalmente consciente e cabe à escola fazer sua parte ofertando a Educação Ambiental em seu caráter formal. $O$ objetivo da educação ambiental é formar sujeitos capazes de compreender o mundo e agir nele de forma crítica (Carvalho, 2010). A maturidade das respostas fornecidas pelos estudantes é fruto de um trabalho que tem como objetivo principal contribuir para a formação de sujeitos ecológicos.

A oferta da Educação Ambiental em maior escala e de forma multidisciplinar está vinculada à capacitação docente, já que infraestrutura, mesmo sendo um aspecto a ser considerado, em se tratando de Educação Ambiental, possui importância secundária. A capacitação docente talvez seja o principal problema a ser solucionado, uma vez que o Professor se sentindo preparado e capaz apresentará elementos dos quais a Educação Ambiental fará parte de sua abordagem contextual. Entre as disposições gerais da Política Nacional da Educação Ambiental está a capacitação de recursos humanos. Não se trata apenas da capacitação através de cursos e metodologias, mas sim da construção de uma identidade pessoal e profissional (Carvalho, 2008).

Segundo Carvalho (2008), o grande desafio da educação ambiental é, pois, ir além da aprendizagem comportamental, engajando-se na construção de uma cultura cidadã e na formação de atitudes ecológicas. A partir do momento em que se conseguir proporcionar a abordagem da Educação Ambiental em caráter multidisciplinar, especialmente durante os ensinos fundamental e médio, a escola cumprirá seu papel para a formação de cidadãos ambientalmente conscientes. Assim, a preservação da biodiversidade será encarada como preocupação de todos e não apenas de uma pequena parcela, que prioriza os interesses coletivos em detrimento dos interesses individuais.

De acordo com Jacobi (2003), é necessária a promoção do crescimento da consciência ambiental, possibilitando participação efetiva da população nos 
processos de decisão, como maneira de fortificar sua responsabilidade no controle e na fiscalização de ações de degradação ambiental.

Não restam dúvidas de que o papel do educador ambiental é fundamental para o amadurecimento massivo da população em questões relacionadas à temática ambiental. Partilhar da identidade ecológica não é necessariamente um pré-requisito para tornar-se educador ambiental, havendo a possibilidade, como já verificado, de percorrer o caminho inverso, ou seja, da Educação Ambiental para a identidade ecológica (Carvalho, 2005).

\section{Considerações finais}

A educação básica brasileira passa por profundas modificações, porém a necessidade de aproximar a Educação Ambiental dos conteúdos escolares já é uma preocupação de longo tempo, da mesma forma que a necessidade de contextualizá-los. Quando os conteúdos são ministrados de maneira contextualizada demonstramse ao aluno as possíveis aplicações práticas em seu cotidiano, sendo essa estratégia considerada importante quando se discutem ações efetivas para a diminuição da evasão escolar, especialmente no ensino médio. Dessa forma, fica evidente que é preciso rever a abordagem dos conteúdos em sala de aula, fazendo com que a educação ambiental esteja presente em caráter preferencialmente interdisciplinar.

A abordagem da educação ambiental no espaço escolar deve respeitar as seguintes etapas: 1) sensibilização, 2) conhecimento dos processos envolvidos, 3) contextualização e prática interdisciplinar, objetivando 4) a alteração de valores e atitudes. Atitude ecológica é algo que está acima de bons comportamentos, e é por esse motivo que a preservação da biodiversidade depende, e muito, do papel da escola para a formação de cidadãos ambientalmente responsáveis. O conceito de desenvolvimento sustentável pode ser interpretado de várias formas, porém é importante ressaltar que meio ambiente não se resume a recursos naturais, nem tão pouco ao que está próximo, pois toda pessoa é parte integrante do meio ambiente (Scardua, 2009).

Preocupa o fato verificado de que os alunos participantes da pesquisa, que vivem em uma das regiões de maior biodiversidade do país, o Pantanal, desconheçam espécies que podem ser encontradas na área urbana de sua cidade. Se realmente é preciso conhecer aquilo que deve ser preservado, é fundamental fazer com que os diferentes segmentos da sociedade conheçam a biodiversidade que os cerca. Torna-se mais fácil aceitar a ideia de que, havendo uma geração que tenha crescido em contato formal com a temática ambiental em idade escolar, práticas ambientais responsáveis serão exigidas, tanto por cidadãos comuns como empresários e representantes políticos.

Somente tornando a biodiversidade conhecida, haverá maior interesse da sociedade pela preservação deste que, sem dúvida, é o maior patrimônio, e cabe a escola fazer a sua parte, através do fomento da Educação Ambiental

\section{Referências bibliográficas}

CARVALHO, I. C. de M. A invenção do sujeito ecológico: identidade e subjetividade na formação dos educadores ambientais. P. 51-63. In: Michèle Sato \& Isabel Carvalho. Educação Ambiental, pesquisa e desafios. Porto Alegre: Artmed, 2005.

CARVALHO, I. C. de M. Educação ambiental: a formação do sujeito ecológico. São Paulo: Editora Cortez, 2008.

\section{CONSTITUIÇÃO DA REPÚBLICA FEDERATIVA DO BRASIL,} BRASÍLIA, DISTRITO FEDERAL. 1988.

GRAIPEL, M. E.; GOULART, F. V. B.; TORTATO, M. A.; SANTOS, L. G. R. \& GHIZONI JUNIOR, I. R. Como preservar nossos valores naturais? Revista Ciência Hoje, v. 42, p. 6669.2008.

GRYNSZPAN, D. Educação em Saúde e Educação Ambiental: uma experiência integradora. Cadernos de Saúde Pública. Rio de Janeiro: , v.15, n.supl 2, p.133 - 138, 1999.

JACOBI, Pedro. Educação Ambiental, cidadania e sustentabilidade. Caderno de Pesquisa, n. 118, pág. 189206.2003.

LEHN, C. R. Meio Ambiente: Onde estamos falhando? Revista Vida \& Arte, São José do Rio Preto, p. 48 - 49, SET. 2009 .

SAUVÉ, L. Uma cartografia das correntes em educação ambiental. P. 17-44. In: Michèle Sato \& Isabel Carvalho. Educação Ambiental, pesquisa e desafios. Porto Alegre: Artmed, 2005.

SCARDUA, V. M. Crianças e Meio Ambiente: A importância da educação ambiental na educação infantil. Revista FACEVV, Vila Velha, n. 3, p. 57-64. 